\title{
Promotion Project for Communication between Artisans and Consumers Supported by Media Technology
}

\author{
Ritsuko Izuhara, Sho Yokokawa, and Shinya Suzuki \\ Kanazawa Institue of Technology \\ 3-1 Yatsukaho, Hakusan-shi, Ishikawa 924-0838, Japan \\ izuhara@neptune.kanazawa-it.ac.jp
}

\begin{abstract}
In many regions of Japan, local artisans continue to make traditional handicrafts using natural materials. However, rapid decreases in consumer demand for these products and the lack of younger successors to continue the craft have become serious problems. Possible explanations for this situation include recent changes in the Japanese lifestyle and gaps between traditional crafts made by artisans and the types of products needed by consumers. To solve these problems, the present study proposes a system to connect artisans and consumers directly. For this purpose, we established a website that facilitates communication between artisans and consumers and the generation of new ideas for craft products. We also launched a promotion event including exhibits using augmented reality (AR) and projection mapping technology to raise awareness of the project among consumers.
\end{abstract}

Keywords: Craft, Promotion, AR, Projection Mapping, Local Activation.

\section{Introduction}

In many regions of Japan, local artisans continue to make traditional handicrafts using natural materials. However, the traditional craft industry has come up against serious problems in recent years. For instance, consumer demand for traditional craft products has decreased rapidly, and as the younger generations move further away from traditional modes of expression and production, artisans have fewer and fewer young successors to continue their craft. Both artisans and local governments are now seeking solutions for these problems.

Kanazawa City, a "City of Hand Craftsmanship Work" located in the northwestern part of Japan, has a distinctive local culture and was accredited as a UNESCO Creative City of Craft and Folk Art in June 2009 [1]. However, even in Kanazawa, which is famous for its handicrafts, the future of traditional local craftsmanship is facing serious problems.

Observation of the situation of the traditional craft industry in Kanazawa in recent years reveals that the output of traditional craft products reached a peak in 1991 and began to decrease rapidly in 1999. One problem in business management for producers is that the number of orders from consumers has decreased [2]. More 
fundamentally, changes in the Japanese lifestyle have created gaps between the traditional crafts made by artisans and products needed by consumers. Due to Western influences as well as the increased emphasis on speed, usefulness, and efficiency in determining value during periods of high economic growth, people now tend to regard traditional crafts as unsuitable for their living environments.

Before we proceed, the definition of crafts should be clarified. Soetsu Yanagi, the founder of the mingei (folk craft) movement in Japan in the late 1920s, defined the category of figurative arts, which includes craft arts, as shown in Fig. 1. Within the category of craft arts, Yanagi defined crafts intended for practical use as "handicrafts for ordinary people", which is one of the original meanings of "craft"[3]. However, in recent years, more value has come to be attached to appreciated crafts such as aristocratic crafts than to practical crafts. The reason for this shift is considered to be the distinction between traditional handicrafts and mass-produced goods. In this study, we follow Yanagi's original definition and aim to promote practical crafts for ordinary people.

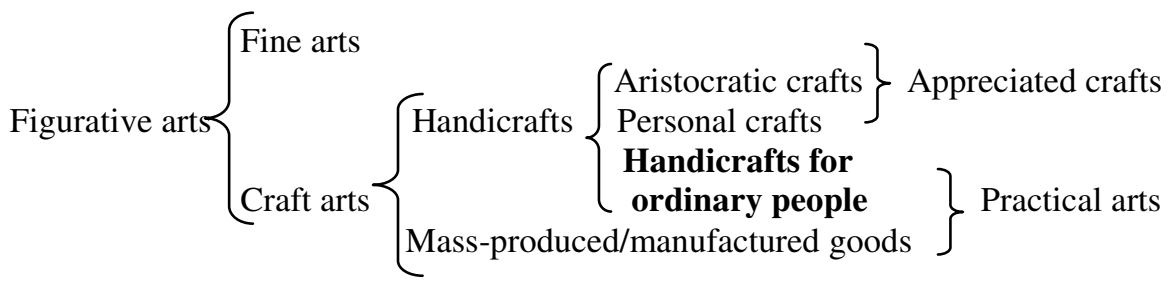

Fig. 1. Categories of figurative arts. Source: S. Yanagi.

To solve the problems currently facing the traditional craft industry, innovative products are needed. However, artisans lack adequate knowledge about the development of new products, and the cost of making trial pieces for new products is high, which prevents artisans from developing and testing new products [2].

The "Innovator Training Unit for Ishikawa Traditional Crafts" program carried out by JAIST is an activity with goals similar to those of the present study. JAIST has established a new education program to teach artisans the marketing methods necessary to develop new products [4]. After completing the program, several artisans attempted to create and market new products, such as USB memory drives made of Kutani ware porcelain. However, in doing so, the artisans had to risk negative evaluations from consumers, as they could not know consumers' evaluations before selling the newly developed products.

In order to provide artisans with more information about consumers' opinions during the development process, we focused on facilitating communication between artisans and consumers. The present study proposes a system that connects artisans and consumers directly and promotes the generation of new ideas for craft products by providing a forum for the exchange of opinions between community members and artisans. 


\section{Fieldwork and Interviews with Artisans}

In order to observe the current state of products being sold in Kanazawa, fieldwork was conducted in shops selling traditional crafts. Interviews were conducted with artisans of Kaga Yuzen, a traditional technique of dyeing fabrics for kimono. The artisans discussed the marketing process of Kaga Yuzen and associated problems. To summarize briefly, wholesale dealers act as intermediaries between producers (artisans) and consumers. Dealers control all marketing flows, including planning and ordering. Consequently, artisans never meet the customers who ultimately use their products, and they cannot receive evaluations directly from customers. In order to improve their products, artisans need to hear customers' opinions; however, artisans do not have an effective way of obtaining this information. In addition, although artisans are interested in the development of new products, they frequently experience difficulty in generating ideas and strategies for product development.

\section{A Community Website as a Bridge between Artisans and Consumers}

We propose the use of a website to promote communication between artisans and consumers and to generate new ideas for craft products. The proposed website represents an open system in which consumers and artisans can develop new ideas for new craft products together through active dialogue. The flow of dialogue is shown in Fig. 2.

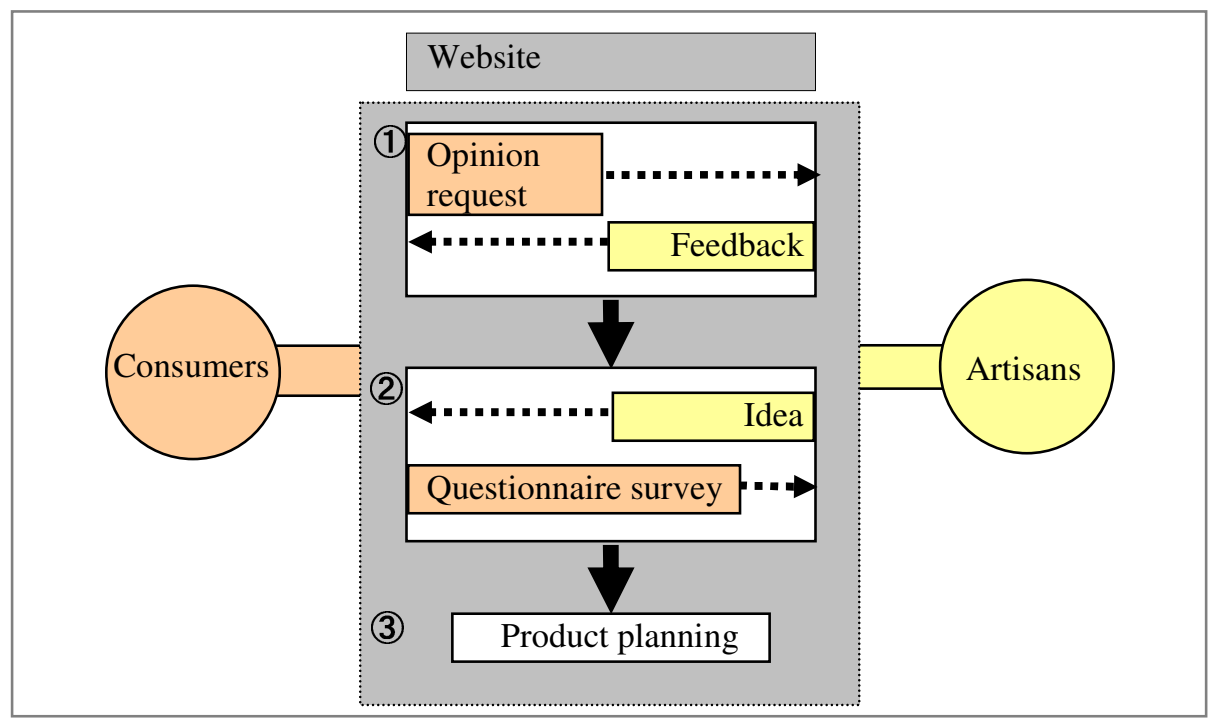

Fig. 2. Dialogue flow between consumers and artisans on the proposed website 
In the first step, unspecified consumers post their opinions and needs regarding traditional craft products. In response, artisans send comments about the consumers' opinions and requests. This dialogue is repeated throughout the website. To initiate this step, a catalyst is required to draw out consumers' opinions. As catalysts, we prepared several themes for discussion and contribution, including practical products such as accessories, clothing and sporting goods. One theme, for example, requested unique ideas for combining modern practical products with traditional crafts; one of the proposed ideas was a snowboard decorated with traditional Kaga Yuzen patterns. The user who suggested this idea commented that a Kaga Yuzen snowboard would be a good representation of the identity of snowboarders in Kanazawa. In this way, the website allows artisans to obtain inspiration for new ideas for products that reflect community members' needs.

In the second step, artisans show their ideas to consumers, and consumers can send feedback to artisans in response. Furthermore, a questionnaire survey is sent to consumers asking them to evaluate the new ideas proposed by artisans. If a new idea receives a favorable review from consumers, a new product planning is formed. On the other hand, when an idea is not favorably evaluated, product planning comes to an end. In this way, the evaluation of planning before production begins is a strict but efficient and effective method of product development.

\section{Website Promotion Event Using Media Technology}

We held a promotion event on December 1-2, 2010 in the entrance hall of the Kanazawa City Office. This event aimed to increase awareness of traditional crafts among younger consumers and to promote our project. The concept behind this event was "Your voice and artisans' skills create new traditional crafts". In order to represent this concept, we presented ideas for new crafts generated by combining traditional crafts with suggestions from ordinary people. As the project was targeted mainly at the younger generation, the event included interactive exhibits using augmented reality (AR) and projection mapping technology to catch the attention of passers-by and to give a prominent impression of the project (Fig. 3). We also distributed flyers with our web address.

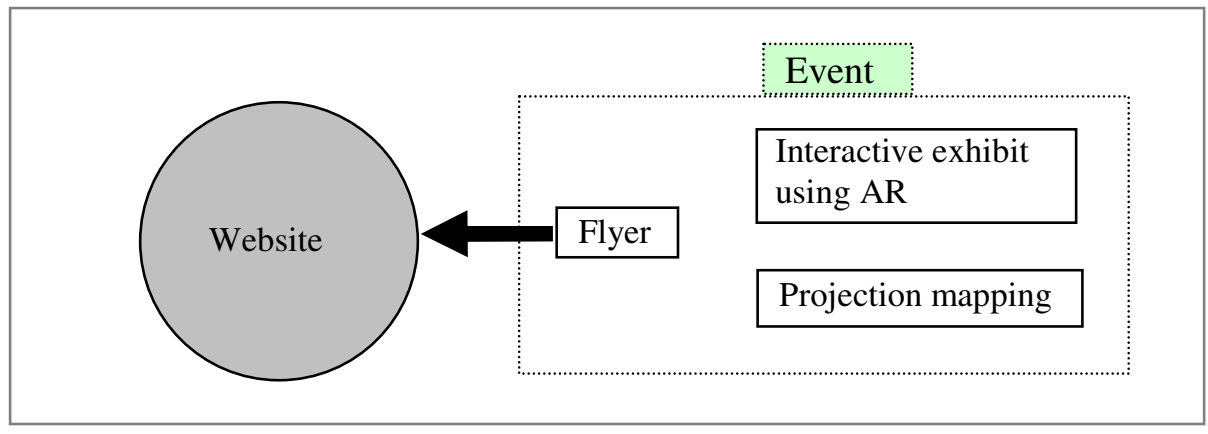

Fig. 3. Promotion event flow 


\subsection{New Ideas for Crafts Presented Using AR}

At the promotion event, we aimed to introduce our project to visitors in order to generate new traditional crafts that reflect the voices of ordinary people, especially younger community members. In order to achieve this, we presented new ideas for crafts generated by combining traditional crafts with popular practical products. Images of these ideas were created using computer graphics (CG) and were displayed on a monitor using AR technology to show realistically shaped objects. We used ARToolKit, the open source software developed by Kato [5].

At the event, four triangular markers representing the four traditional crafts of Kaga Yuzen (dyeing), Kaga Shikki (lacquerware), Kaga Zougan (metal inlay) and Kaga Shishu (needlework) were prepared. Furthermore, four more triangular markers representing the four popular practical products of aroma goods, key cases, tableware and accessories were also prepared. Visitors were asked to choose one marker from each group. By fitting the two triangular markers together, visitors created a square marker (Fig. 4), which represented a new idea that combined one traditional craft with one popular product.

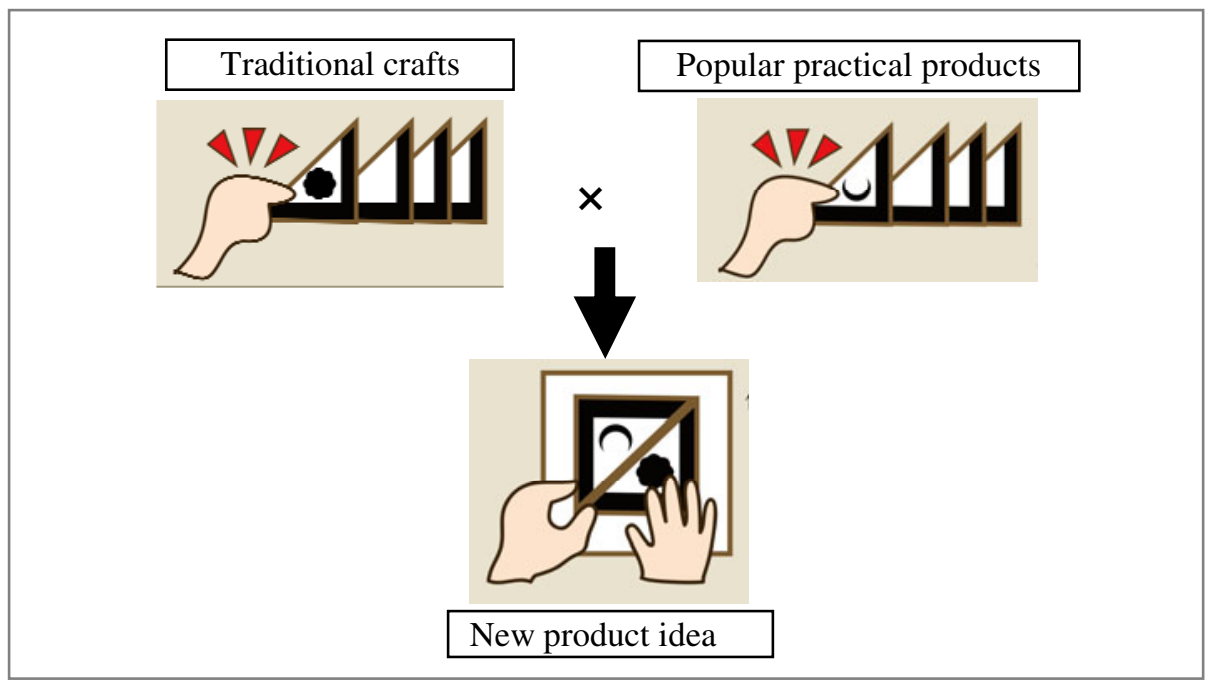

Fig. 4. Combining AR markers to form new product ideas

The combination of an aroma ball with the Kaga Shishu needlework technique is displayed on the left side of Figure 5. By fitting together the two triangular markers and placing the resulting square marker in front of the camera, a new product combining elements of each of the two triangular markers is displayed on the screen. The right side of Figure 5 shows other new ideas, including a tumbler with Kaga Yuzen patterns, a key case made with Kaga Shikki lacquer, and a bracelet with Kaga Zougan inlay.

Usually, producing a prototype is expensive and time consuming. However, using $\mathrm{CG}$ and AR technology allows product planning to proceed easily and at lower cost. 


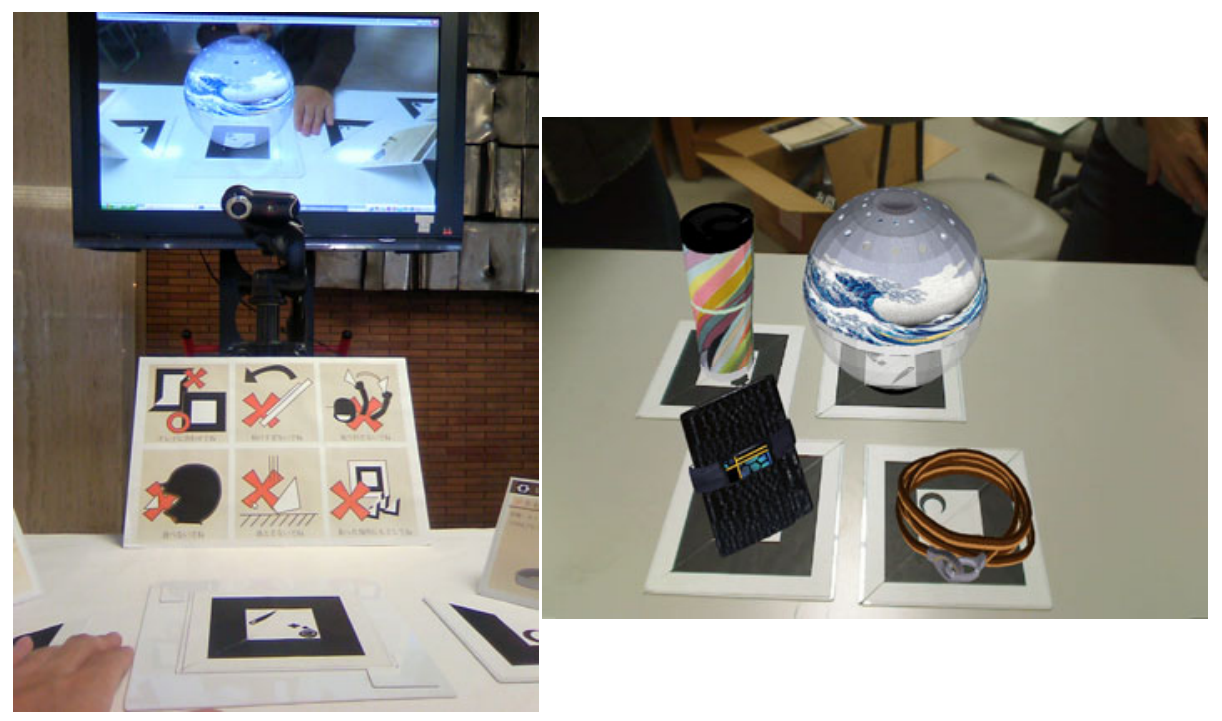

Fig. 5. Interactive AR exhibit showing new craft ideas

\subsection{Simulation of New Product Ideas with Projection Mapping}

In another exhibit at the event, projection mapping was used to simulate new ideas for traditional crafts. Projection mapping is a technique in which a two-dimensional image is projected onto a three-dimensional object. The projected image is fitted onto the object and viewers perceive the projected image as real. The display configuration of this exhibit is shown in Figure 6. In order to create the projected image, a scene was rendered using CG in which the desired objects were arranged in the same manner as the real three-dimensional objects.
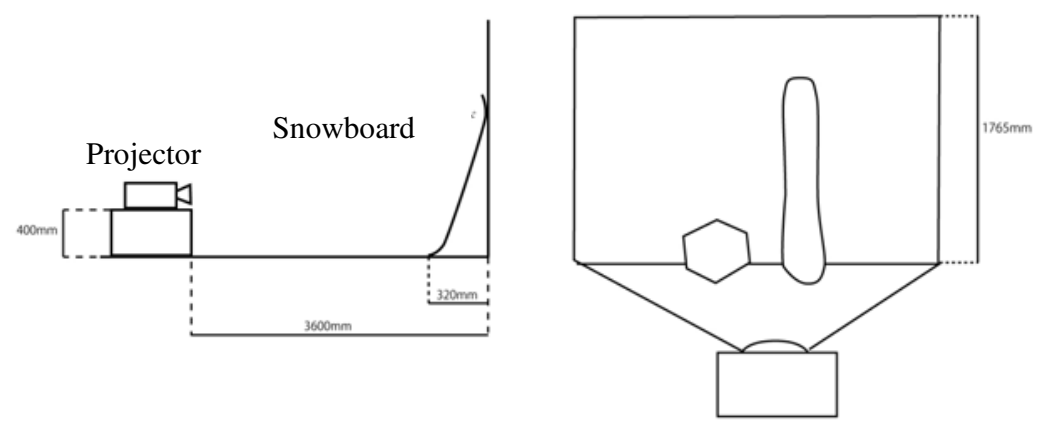

Fig. 6. Display configuration for projection mapping 
We used projection mapping to display the idea of the Kaga Yuzen snowboard (Fig. 7). We created a scene with a snowboard using 10 patterns created by Kaga Yuzen artisans. The CG images were then projected onto a real snowboard in sequence.

Using this simulation method has two advantages: first, participants are able to view full-scale prototypes of new products; and second, artisans can make experimental mock-ups easily.
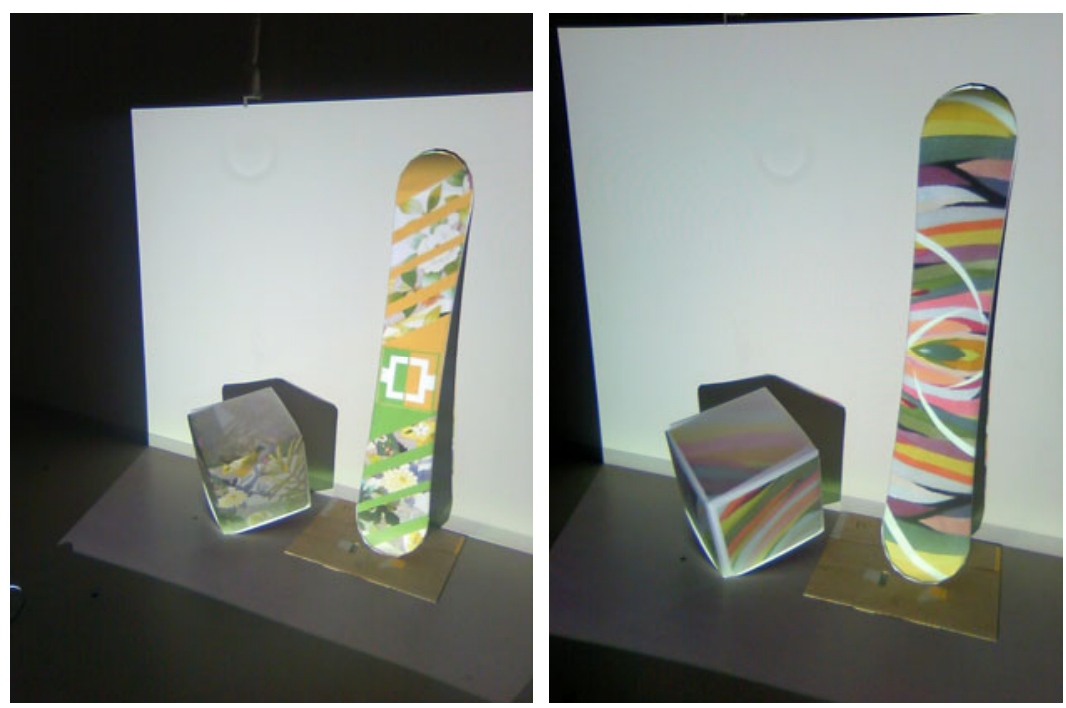

Fig. 7. Projection mapping of Kaga Yuzen snowboard

At the event, we also administered a questionnaire survey. Sixty percent of participants were in their 20s and 30s. As a result, almost all of the participants were able to understand the purpose of the project, and most of them found the AR and projection mapping exhibits interesting. In particular, we asked participants to evaluate projection mapping of the Kaga Yuzen snowboard. One participant responded that the snowboard could indicate the regional characteristics of a snowboarder in ski sites. Although the design is based on traditional Kaga Yuzen patterns, the product design seems novel because the patterns are applied to a modern sporting product.

\section{Conclusion}

In the present study, a website with the aim of generating new ideas for craft products through the exchange of opinions between consumers and artisans was proposed and a promotion event using AR and projection mapping technology to raise awareness of the project was reported. 
After the promotion event, we received several inquiries directly from artisans who wanted to know community members' opinions through the website in order to expand their work fields. However artisans were worried about copyright issues, such as other artisans stealing people's ideas on the website. Artisans' comments offered insight into issues such as which opinions are useful and whether ideas should be shared in an open system or whether it is more important to maintain originality by keeping the idea-generation process under closer control.

We hope to proceed with our project in the future in order to continue to help artisans to adapt to the changing demands of modern society.

Acknowledgments. I would like to thank Masato Zenke and Satoshi Nishimura, staff of the City of Kanazawa, for their help in our projects.

\section{References}

1. Kanazawa Creative City Promotion Committee, Kanazawa Creative City Promotion Program 1 (2010)

2. City of Kanazawa, Action Plan of Kanazawa Traditional Craft Industry, 8-15 (2010)

3. Yanagi, S.: Kougei Bunka. Iwanami Bunko, pp. 26-29 (1985)

4. Ogata, S., Nakamori, Y., Kobayashi, T.: MOT Educational Program for Traditional Craft in Ishikawa. The Japan Society for Science Policy and Research Management, 502-505 (2007)

5. Kato, H.: ARToolKit: Library for Vision-based Augmented Reality. IEICE, PRMU, 79-86 (2002) 